\title{
The influence of deep frying using various vegetable oils on acrylamide formation in sweet potato (Ipomoea batatas L. Lam) chips
}

\begin{abstract}
The objective of this study was to evaluate the precursors of acrylamide formation in sweet potato (SP) (Ipomoea batatas L. Lam) chips and to determine the effect of different types of vegetable oils (VOs), that is, palm olein, coconut oil, canola oil, and soya bean oil, on acrylamide formation. The reducing sugars and amino acids in the SP slices were analyzed, and the acrylamide concentrations of SP chips were measured. SP chips that were fried in a lower degree of unsaturation oils contained a lower acrylamide concentration $(1443 \mathrm{\varepsilon g} / \mathrm{kg})$, whereas those fried with higher degree of unsaturated oils contained a higher acrylamide concentration $(2019 \mathrm{\varepsilon g} / \mathrm{kg})$. SP roots were found to contain acrylamide precursors, that is, $4.17 \mathrm{mg} / \mathrm{g}$ glucose and $5.05 \mathrm{mg} / \mathrm{g}$ fructose, and $1.63 \mathrm{mg} / \mathrm{g}$ free asparagine. The type of VO and condition used for frying, significantly influenced acrylamide formation. This study clearly indicates that the contribution of lipids in the formation of acrylamide should not be neglected.
\end{abstract}

Keyword: Acrylamide; Free asparagines; Reducing sugars; Sweet potato chips; Vegetable oils 